\title{
Advances in $\mathrm{Y}-90$ radioembolization for the treatment of hepatocellular carcinoma
}

\author{
Andrew J. Woerner, Guy E. Johnson \\ Department of Radiology, Section of Interventional Radiology, University of Washington, Seattle, WA 98195, USA. \\ Correspondence to: Dr. Guy E. Johnson, MD, PharmD, Department of Radiology, Section of Interventional Radiology, University \\ of Washington, 1959 Northeast Pacific Street, Seattle, WA 98195, USA. E-mail: gej@uw.edu
}

How to cite this article: Woerner AJ, Johnson GE. Advances in Y-90 radioembolization for the treatment of hepatocellular carcinoma. Hepatoma Res 2022;8:2. https://dx.doi.org/10.20517/2394-5079.2021.122

Received: 9 Sep 2021 First Decision: 1 Nov 2021 Revised: 15 Nov 2021 Accepted: 24 Nov 2021 Published: 6 Jan 2022

Academic Editor: Georgios Tsoulfas Copy Editor: Yue-Yue Zhang Production Editor: Yue-Yue Zhang

\begin{abstract}
Hepatocellular carcinoma remains a prominent cause of cancer-related mortality globally. Transarterial yttrium-90 radioembolization is a versatile therapy and plays an important role in the treatment of hepatocellular carcinoma. This review summarizes the establishment of radioembolization in the hepatocellular carcinoma treatment paradigm, treatment considerations across cancer stages, and recent advances in evidence.
\end{abstract}

Keywords: Hepatocellular carcinoma, radioembolization, yttrium-90, dosimetry, radiation segmentectomy

\section{BACKGROUND}

Primary liver cancer is the fourth leading cause of cancer-related mortality in the world, and its 18 percent five-year survival rate stands only behind pancreatic cancer ${ }^{[1]}$. Unlike the recent declining mortality rates of other common cancers in the United States, mortality from primary liver cancer increased by 0.5 percent from 2014 to $2018^{[2,3]}$. Of the primary liver cancers (hepatocellular carcinoma, intrahepatic cholangiocarcinoma, and combined hepatocellular cholangiocarcinoma), hepatocellular carcinoma (HCC) accounts for $85 \%-90 \%{ }^{[4]}$.

The Barcelona Clinic Liver Cancer (BCLC) schema is a widely accepted staging system for HCC $^{[5,6]}$. The BCLC staging system is divided into five categories: very early (0), early (A), intermediate (B), advanced (C), and terminal (D). Tumor burden is characterized by nodule number and size, the presence of 
macrovascular invasion, and any extrahepatic spread. The mainstay curative therapy remains surgical resection or liver transplantation; however, many patients do not qualify due to advanced stage, social factors, or scarcity of liver transplant donors. For patients with unresectable HCC, locoregional therapies play an essential role. Catheter-based therapy such as transarterial chemoembolization has been historically reserved for patients with BCLC intermediate-stage disease. A distinct, well-established catheter-based therapy for patients with HCC, transarterial radioembolization, relies on the hepatic arterial and tumor vascular bed for internal delivery of radiotherapy using yttrium-90 (Y90). With increasing worldwide use, radioembolization has become an essential therapy in the treatment of HCC and is supported by National Comprehensive Cancer Network guidelines ${ }^{[7]}$. Historically, transarterial radioembolization with Y90 had been reserved for the treatment of advanced-stage disease; however, more recent data support its incorporation into the treatment of early and intermediate stages ${ }^{[8-11]}$.

Nonsurgical candidates who have BCLC stage 0 or A tumors are recommended for ablation, most frequently performed in a percutaneous, image-guided fashion ${ }^{[12,13]}$. Transarterial therapies, including radioembolization and chemoembolization, have traditionally been reserved for intermediate-stage disease. Chemoembolization initially became the standard of care for this patient population in 2002 following two randomized controlled trials comparing it to supportive care, while radioembolization was typically employed in patients not deemed appropriate candidates for chemoembolization ${ }^{[14,15]}$. This led to clinical investigations of radioembolization more commonly performed in patients of more advanced stages ${ }^{[16,17]}$.

With increasing interest and utilization of radioembolization, developed techniques have improved outcomes and lowered toxicity. This review provides an introduction to Y90 radioembolization for HCC across the spectrum of cancer stages with a focus on the data arising from newer techniques and dosimetric approaches.

\section{Y90 radiochemistry and devices}

Y90, with a 64.2 h physical half-life, decays to zirconium-90 by emission of a beta particle. When Y90 microspheres are embedded in the hepatic microvasculature, this beta particle emits energy with a mean and maximum tissue penetration of $2.5 \mathrm{~mm}$ and $11 \mathrm{~mm}$, respectively ${ }^{[18,19]}$. Using Medical Internal Radiation Dose (MIRD) methods, one gigabecquerel of Y90 delivers a radiation of dose 50 Gy to $1 \mathrm{~kg}$ of tissue $\mathrm{e}^{[20]}$.

Currently, there are two available Y90 devices: resin Y90 microspheres (SIR-Spheres, Sirtex Medical, Sydney, Australia) and glass Y90 microspheres (TheraSphere, Boston Scientific Corporation, Marlborough, MA). Both devices are similar in size, measuring 20-60 $\mu \mathrm{m}$ and 20-30 $\mu \mathrm{m}$ for the resin and glass devices, respectively. The resin Y 90 microspheres are surface-coated with Y 90 while the radioisotope is integral to the glass device; the effect of this feature is higher activity per microsphere for the glass device $(2500 \mathrm{~Bq} / \text { microsphere } v \text { s. } 50 \mathrm{~Bq} / \text { microsphere })^{[18]}$. This results in a necessarily higher quantity of resin microspheres infused for a given radiation dose, resulting in a greater embolic effect, although both devices are considered micro-embolic. The glass device is FDA-approved for the treatment of HCC. Both devices have been used in the treatment of HCC, although the radiation dosimetry may differ between devices ${ }^{[21]}$.

\section{Y90 dosimetry}

Utilization of proper dosimetry during treatment planning is of critical importance for the optimization of Y 90 radioembolization. Integral to radioembolization is a pre-treatment planning procedure and hepatic angiogram or Y90 "mapping angiogram". The goals of the mapping angiogram include achieving an understanding of the hepatic and mesenteric arterial anatomy, identifying target arteries that require treatment, and searching for extrahepatic arteries that may predispose to nontarget radioembolization. The latter may include the right or accessory left gastric artery, the retroduodenal artery, or occasionally the 
falciform artery, depending on the necessary catheter position at the time of radioembolization. If any such extrahepatic arteries are identified, prophylactic coil embolization of the vessel may be considered to protect the nontarget tissue, although coil embolization has decreased in contemporary practice. Another paramount goal of the mapping angiogram is the estimation of the fraction of microspheres that may escape the hepatic vascular bed and embolize to the pulmonary circulation [termed the lung shunt fraction (LSF)]. Presently, this latter step is achieved using a surrogate of Tc-99 macroaggregated albumin (MAA) to simulate the Y 90 microspheres. Following infusion of the Tc-99 MAA into the tumor-bearing hepatic lobar artery, the patient undergoes planar scintigraphy as well as Single-Photon Emission Computed Tomography/Computed Tomography (SPECT/CT) that allows for determination of the distribution of the Tc-99 MAA and estimation of the LSF [Figure 1]. In addition, the SPECT/CT images allow for advanced dosimetric analysis and planning.

Foundational to this principle are previous studies that demonstrated a relationship between radiation dose and tumor response. Early empirical studies established the basis for dosimetry calculations, which relied on estimating the absorbed dose of an "average" individual, even allowing a wide range of delivered doses ${ }^{[22-24]}$. The standard dosimetric approach in treating HCC prescribes a dose of 120 Gy to the perfused volume of treated liver tissue. This balances the safety of necessarily treating nontarget normal hepatic parenchyma against the desire to increase tumor dose. This dosimetric approach based on the MIRD model assumes that the dose delivered by the Y90 microspheres is distributed uniformly throughout the treated tissue. This "single compartment" approach oversimplifies the reality of the situation in which there is the inherently nonuniform distribution of the Y90 microspheres, and therefore a nonuniform dose. In reality, the hypervascular tumor receives a higher dose, and the normal parenchyma receives a lower dose than the dose averaged across the entire volume. Recognizing this, a multi-compartment dosimetric approach supports the separate evaluation of tumor and normal liver doses separately. Subsequent studies and advancements in dosimetry have allowed for the establishment of higher targeted thresholds as well as more accurate patient-specific delivered doses. Several early studies converged on a tumor-absorbed dose near $200 \mathrm{~Gy}$ to achieve an objective response for $\mathrm{HCC}^{[25-29]}$. Based on the MIRD model, more recent data suggest a minimum dose of $400 \mathrm{~Gy}$ as a threshold dose required for complete response ${ }^{[30]}$. Understanding dosimetry is important not only for optimizing tumor responses but also for avoiding toxicity to normal liver parenchyma. Radiation delivered to healthy tissue may lead to radioembolization-induced liver disease, radiation-induced hepatic fibrosis, and other extrahepatic manifestations $s^{[31-33]}$. Thus, intrinsic to optimal outcomes is maximizing tumor dose while minimizing nontumor parenchymal radiation exposure. Empiric limitations of radiation segmentectomy to up to two hepatic segments have been associated with a good safety profile. However, in the future, risk assessment may be based on the volumetric assessment of target normal tissue and underlying liver function ${ }^{[34]}$.

\section{RADIOEMBOLIZATION IN EARLY-STAGE HCC}

Advancements in radioembolization have shown promising results in treating solitary HCC and led to changes in practice. For patients with solitary tumors but who are not candidates for other therapies such as thermal ablation or resection, ablative radioembolization or "radiation segmentectomy" has offered response rates similar to other curative-intent therapies for $\mathrm{HCC}^{[9,10,35-38]}$ [Table 1]. Relying on the characteristic physics of Y90 decay, radiation segmentectomy allows for the selective infusion of the Y90 microspheres into the tumor-bearing segment of the liver [Figure 2]. Because of the limited beta-radiation penetration beyond the small volume of treated tissue that includes the tumor, the prescribed dose of Y 90 can be dramatically escalated, and response rates improved. Toxicity remains limited due to the small volume of treated normal liver tissue [Table 1]. Riaz et al. ${ }^{[11]}$ first described this approach in 2011, defining the therapy as radioembolization of two or fewer hepatic segments, and ultimately demonstrated safety and 
Table 1. Studies on radiation segmentectomy for hepatocellular carcinoma

\begin{tabular}{lllllll}
\hline Ref. & $\mathbf{N}$ & Tumor & Toxicity $^{\star}$ & OR (\%) & CR (\%) & TTP \\
\hline Salem et al. ${ }^{[36]}, 2021$ & 162 & $<8 \mathrm{~cm}$ & $1.8 \%$ & 88.3 & 84 & Not reached \\
Toskich et al. $^{[38]}, 2021$ & 37 & $2.3 \mathrm{~cm}$ & 0 & 90 & 76 & Not reported \\
Arndt et al. $^{[37]}, 2020$ & 34 & $\leq 4 \mathrm{~cm}$ & $9.1 \%$ & 88 & 88 & Not reported \\
Biederman et al. $^{[54]}, 2018$ & 55 & $\leq 3 \mathrm{~cm}$ & $5.5 \%$ & 87 & 92 & Not reported \\
Lewandowski et al. $^{[9]}, 2018$ & 70 & $\leq 5 \mathrm{~cm}$ & $1.4 \%$ & 90 & 59 & 2.4 years \\
Padia et al. ${ }^{[10]}, 2017$ & 101 & $\leq 8.3$ & $4 \%$ & 97 & 92 & 19 months \\
Biederman et al. ${ }^{[35]}, 2017$ & 41 & $\leq 3 \mathrm{~cm}$ & $7.3 \%$ & 97.5 & 85 & 11.1 months \\
Padia et al. ${ }^{[41]}, 2014$ & 20 & $\leq 7.1 \mathrm{~cm}$ & 0 & 95 & 95 & 10.6 months \\
Vouche et al. $^{[25]}, 2014$ & 102 & $\leq 5 \mathrm{~cm}$ & $6.3 \%$ & 86 & 47 & 33.1 months \\
Riaz et al. ${ }^{[1],}, 2011$ & 84 & T1-T4 & $6 \%$ & 81 & Not reported & 13.6 months \\
\hline
\end{tabular}

*Toxicity was grade $\geq 3$ bilirubin toxicity within 90 days unless timeframe was unreported. Response evaluations were by modified Response Evaluation In Solid Tumors (mRECIST) or European Association for the Study of Liver (EASL) criteria. N: Number; OR: objective response; CR: complete response; TTP: time to progression.
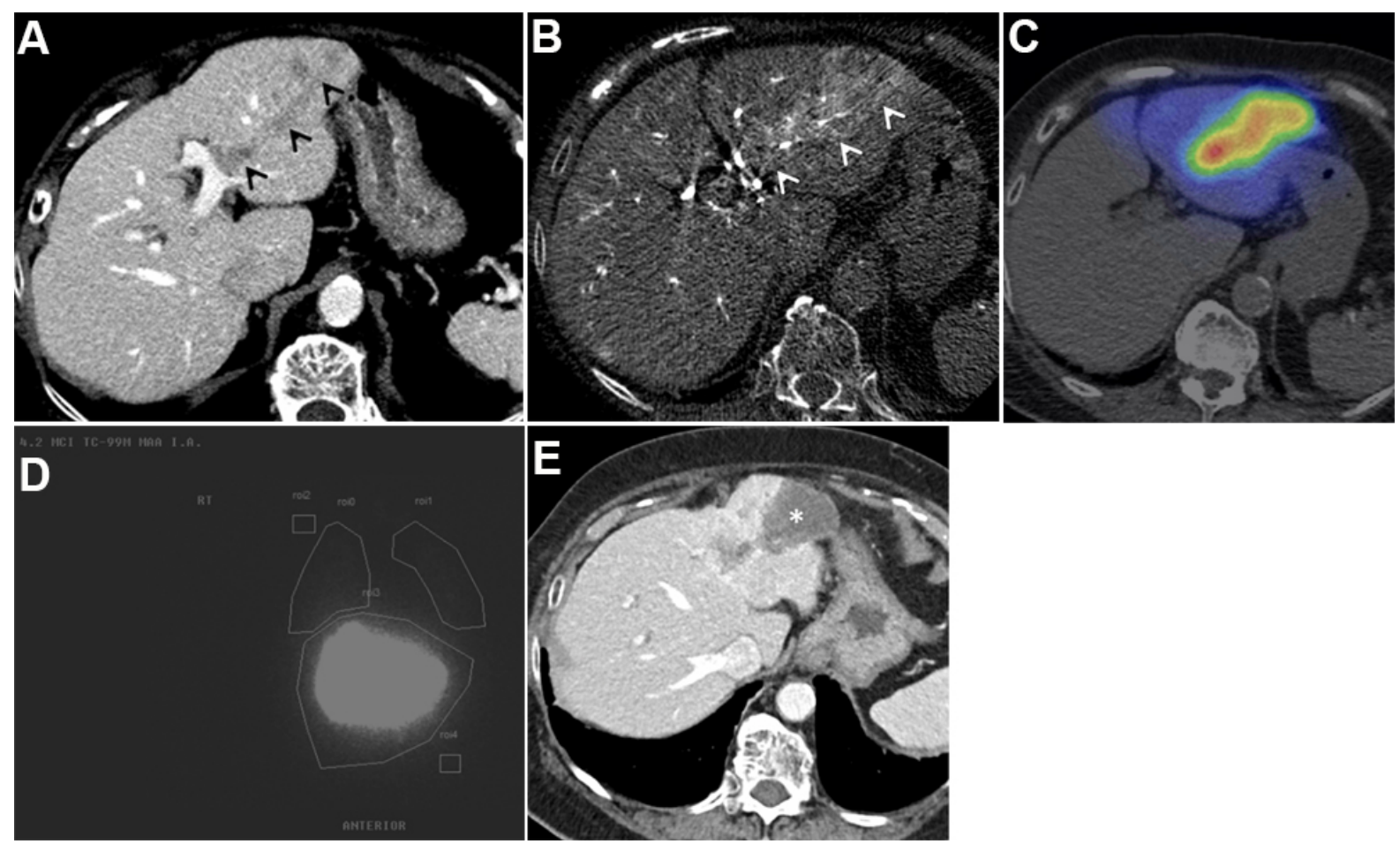

Figure 1. Hepatitis C cirrhosis in an 88-year-old woman complicated by HCC. Initial alpha fetoprotein (AFP) tumor marker was 9736. (A) Venous phase contrast-enhanced CT liver shows a nodular HCC with vascular invasion, expanding the segment 3 portal vein (black arrowheads). (B) C-arm computed tomography image during Y90 mapping angiography shows arterial enhancement of the HCC involving the portal vein (white arrowheads). (C) Single-photon emission computed tomography image fused with computed tomography image shows preferential deposition of Tc-99m MAA radiotracer in the tumor compared to the normal parenchyma. (D) Planar images show Tc-99m MAA deposition, primarily in the liver. Regions of interest are created over the lungs and liver to determine the lung shunt fraction ( $2 \%$ in this case). (E) Following radioembolization of the left hepatic artery, venous phase contrast-enhanced CT liver shows complete necrosis of the tumor (asterisk), and the AFP normalized to 4. MAA: Macroaggregated albumin; AFP: alphafetoprotein.

efficacy. The median dose delivered to the tumor was calculated as $1214 \mathrm{~Gy}$, with a median time to progression (TTP) and overall survival (OS) of 13.6 months and 26.9 months, respectively. 

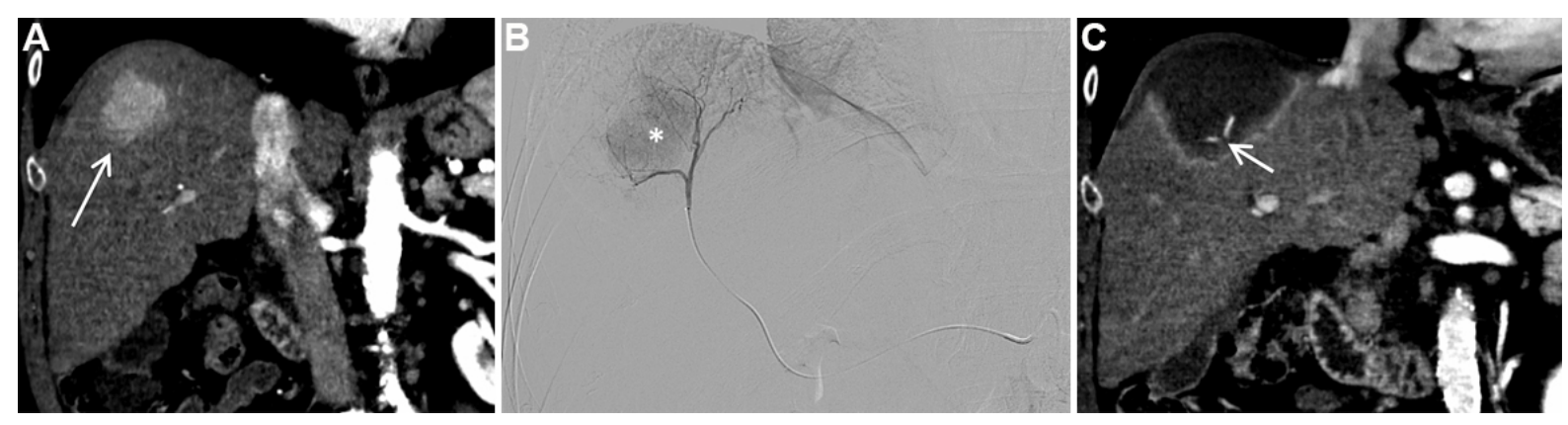

Figure 2. Radiation segmentectomy of a $3.5 \mathrm{~cm} \mathrm{HCC}$ in a 71-year-old-man with hepatitis $\mathrm{C}$ cirrhosis. (A) Coronal contrast-enhanced computed tomography image demonstrates an arterial phase hyperenhancing HCC. (B) Right hepatic digital subtraction arteriogram with contrast injection via the microcatheter located in the distal segment 8 artery at the time of radioembolization. Note the tumor vascularity (asterisk). (C) Coronal contrast-enhanced computed tomography image 6 months after radioembolization shows a wedgeshaped region of necrosis subtending the treated artery. Note the bifurcating artery corresponding to the artery depicted in C (arrow).

With percutaneous ablation already established as a curative-intent therapy, investigators sought to compare outcomes with radiation segmentectomy for HCC. A comparative study between radiation segmentectomy and chemoembolization combined with microwave ablation in tumors $\leq 3 \mathrm{~cm}$ showed no statistical difference in OS between the two modalities ${ }^{[35]}$. However, radiation segmentectomy is free of some limitations encountered with thermal ablation. For example, radiation segmentectomy is performed under moderate sedation and does not require general anesthesia, which may be required for thermal ablation. Additionally, it is not limited by concerns of peritumoral veins that may create a heat sink phenomenon with thermal ablation and lead to local recurrence ${ }^{[39]}$. Further, response rates from thermal ablation decrease with tumors $>3 \mathrm{~cm}$, while this limitation is not seen with radiation segmentectomy ${ }^{[40]}$. In studies inclusive of tumors $>3 \mathrm{~cm}$, objective response rates ranged from $86 \%$ to $97 \%$ with TTP from 10.6 months to 33.1 months $s^{[9,10,25,41]}$. Finally, needle tract seeding of tumor is a rare but known complication of thermal ablation that, in some centers, causes hesitation to perform ablation for patients who are listed for liver transplant (LT). Radioembolization is not associated with this risk.

Understanding Y90 dosimetry is vital in radiation segmentectomy. Vouche et al..$^{[25]}$ evaluated the treatment response of 102 patients who underwent Y90 radiation segmentectomy for HCC not amenable to thermal ablation or resection. A subgroup of 33 patients ultimately underwent liver transplants allowing for pathologic correlation with treatment dose. Complete pathologic necrosis (CPN) was achieved at a greater rate in those treated with a mean dose greater than 190 Gy (14 of $21 v s .3$ of $12, P=0.03$ ), establishing a potential threshold dose for further investigation. A recent study analyzed 45 patients who underwent radiation segmentectomy and subsequent $\mathrm{LT}$ or surgical resection and therefore had tumors available for pathologic evaluation ${ }^{[30]}$. All patients that received a dose greater than $400 \mathrm{~Gy}$ demonstrated CPN, indicating a new target threshold dose for radiation segmentectomy.

The recent, multicenter retrospective LEGACY study evaluated radiation segmentectomy in 162 patients across three sites with localized and unresectable $\mathrm{HCC}^{[36]}$. The objective response rate was $88 \%$. At 24 months, the mRECIST local progression rate was 0 , and progression-free survival was $94 \%$. Overall survival for the entire group was $95 \%$ and $87 \%$ at 24 and 36 months, respectively, and survival rates were similar between those proceeding to transplant or resection compared to patients who did not.

\section{RADIOEMBOLIZATION IN INTERMEDIATE AND ADVANCED STAGE HCC}

Radioembolization provides an alternative to chemoembolization for patients with intermediate-stage HCC. Because of its mechanism of action and the microembolic nature of the Y90 microspheres, 
radioembolization is better tolerated than chemoembolization and is associated with improved quality of $\operatorname{life}^{[42,43]}$. Radioembolization is an outpatient procedure and does not require inpatient admission that can be necessary after chemoembolization. In 2018, a meta-analysis comparing the two modalities demonstrated overall similar survival outcomes in unresectable $\mathrm{HCC}^{[44]}$. However, it is noted that there is considerable heterogeneity between the three randomized clinical trials evaluated. Retrospective data show that radioembolization demonstrates a longer TTP in comparison to chemoembolization ${ }^{[43]}$. The durability of radioembolization was prospectively confirmed in a randomized phase II trial comparing chemoembolization to radioembolization in 45 BCLC intermediate-stage patients and early-stage patients ineligible for surgery or ablation ${ }^{[8]}$. Results showed a TTP of $>26$ months compared to 6.8 months $(P=$ $0.0012)$. Trial investigators also noted that patients randomized to radioembolization benefitted from a higher transplantation rate ( $54 \%$ vs. $30 \%$ ). Given the limited enrollment, detection of a survival difference would not be expected, and median survival between treatment arms was similar (18.6 months vs. 17.7 months, $P=0.99$ ). Although there are no data showing a survival difference between radioembolization and chemoembolization for intermediate-stage HCC presently, benefits including the improved tolerability and durability of the therapy have led some institutions to adopt radioembolization as a primary therapeutic consideration for patients with $\mathrm{HCC}^{[45]}$.

Maturing data support improved outcomes using advanced dosimetry in radioembolization in both intermediate and advanced-stage HCC populations. Studies on prospective tumor dose quantification using ${ }^{99 m} \mathrm{Tc}$-MAA suggested a predictive value, with higher overall survival with greater-than-standard tumor doses (> $205 \mathrm{~Gy})^{[46,47]}$. This foundational work led to the DOSISPHERE-01 trial, a multicenter randomized phase II trial that compared treatment responses between standardized and personalized (> $205 \mathrm{~Gy}$ ) dosimetric approaches in patients with unresectable locally advanced $\mathrm{HCC}^{[26]}$. The dosimetry was based on the distribution of ${ }^{99 \mathrm{~m}}$ Tc-MAA infused during mapping angiography. After the mapping angiogram, patients were randomized to receive radioembolization using standard (single compartment) dosimetry of 120 Gy or personalized (multi-compartment) dosimetry of at least 205 Gy to the index tumor. In the latter group, the dose to the normal liver parenchyma was limited to $120 \mathrm{~Gy} .90 \%$ and $87 \%$ of the patients had advanced HCC in the standard and personalized dosimetry groups, respectively. $72 \%$ and $65 \%$ had portal vein tumor invasion in the standard and personalized dosimetry groups, respectively. Mean index tumor size was similar at $11.1 \mathrm{~cm}$ and $10.6 \mathrm{~cm}$ in the two groups. At interim analysis, the trial was interrupted for efficacy. Radioembolization using personalized dosimetry resulted in a significantly higher objective response rate $(71 \%$ vs. $36 \%, P=0.0074)$. Median OS was 26.6 months in the personalized dosimetry group compared with 10.7 months in the standard dosimetry group [HR = 0.421, (95\%CI: 0.215-0.826), $P=$ 0.0096].

Two randomized phase III trials of patients with HCC compared outcomes of sorafenib vs. radioembolization using the resin $Y_{90}$ device. These trials were designed and conducted in the era when sorafenib was the first-line systemic therapy for HCC. The SARAH trial, conducted in Europe, included patients with locally advanced HCC, new HCC not eligible for curative-intent therapy, or patients who had been unsuccessfully treated with chemoembolization ${ }^{[48]}$.On an intention-to-treat (ITT) basis, there was no difference in OS between the groups with a median survival of 8 and 9.9 months in the radioembolization and sorafenib arms, respectively $(P=0.18)$. Of those randomized to receive radioembolization, $22 \%$ did not receive the assigned therapy, and instead, $49 \%$ of those patients received sorafenib. The SIRveNIB trial was conducted in a similarly heterogeneous population with HCC in the Asia-Pacific region of the world ${ }^{[49]}$. This trial included patients with BCLC intermediate- and advanced-stage disease. As with the SARAH trial, there was no difference in survival between the two arms. Median OS in the ITT population was 11.3 and 10.4 months in the radioembolization and sorafenib arms, respectively $(P=0.27)$. In another parallel to the 
SARAH trial, a significant proportion of the patients randomized to receive radioembolization did not receive the assigned therapy, which is $29 \%$ in this case. However, in SIRveNIB, patients with advanced HCC showed better survival with radioembolization than sorafenib (9.2 months $v s .5 .8$ months, $P=0.0475)$.

While there are cohort and level II data supporting the use of radioembolization in advanced HCC, many were disappointed by the results of the SARAH and SIRveNIB trials, which drew commentary. For example, in both trials, patients were randomized before the mapping procedure, which may have subsequently revealed a contraindication to radioembolization (such as an unacceptably high LSF); this would consequently dilute a treatment effect in the ITT analysis. Y90 dosimetry was based on a body-surface-area formula, although in SIRveNIB, a partition model may have been used for some patients. Nevertheless, whatever the dosimetric method, dose-related endpoints were not incorporated, which is problematic given the dose-response relationship of HCC to radiation. It is clear that in future trials, dose-related endpoints will be important, as will the recognition that dose tailoring or personalized dosimetry is essential, as was clearly shown in the DOSISPHERE-01 trial.

In patients with advanced-stage HCC and limited (segmental or lobar) vascular invasion but with a relatively confined disease, radiation segmentectomy may be a therapeutic option [Figure 1]. In a relatively large retrospective study comparing outcomes in patients treated with segmental radioembolization (radiation segmentectomy) $v s$. segmental chemoembolization, index tumor complete response rates were $92 \%$ and $74 \%$, respectively $(P<0001)^{[10]}$. In this study, $46 \%$ of patients treated with radioembolization had advanced-stage HCC had $18 \%$ showed portal venous invasion. However, the authors found no difference in response rates in subgroup analysis. Further, radiation segmentectomy response rates remain robust in solitary advanced-stage HCC when the stage is due to a compromised performance status ${ }^{[36]}$.

\section{RADIOEMBOLIZATION IN SPECIAL APPLICATIONS}

\section{Bridging treatment to liver transplantation}

The importance of liver transplantation bridging therapies is highlighted by the $10 \%-23 \%$ rate of progression of HCC while awaiting transplantation ${ }^{[5,551]}$. However, geographic regions with shorter wait times have demonstrated decreased OS, which may reflect an insufficient wait time to assess for aggressive tumor biology ${ }^{[52]}$. The United Network for Organ Sharing (UNOS) staging criteria now incorporates a 6month observational period for patients to be allocated exceptional Model for End-Stage Liver Disease points based on the presence of $\mathrm{HCC}^{[3]}$. The American Association for the Study of Liver Diseases suggests therapy for bridging to transplant in patients listed for LT within UNOS T2 (Milan) transplant criteria to decrease disease progression and consequent dropout from the waiting list ${ }^{[53]}$. Another goal of bridging therapy is to prevent post-LT HCC recurrence. Therefore, durable and effective therapies are essential for successful bridging to LT. In addition to the data showing increased time to secondary therapy ${ }^{[54]}$ and phase II data showing more robust durability of radioembolization over chemoembolization, several prior case series exhibit promising results for those treated with radioembolization ${ }^{[36,55,56]}$. In two prior studies of patients undergoing radioembolization prior to transplantation, all patients who initially met Milan criteria went on to receive a transplant ${ }^{[55,56]}$. Investigators compared 172 patients receiving either chemoembolization or radioembolization prior to liver transplantation ${ }^{[57]}$. Despite the longer time to transplantation in the Y90 treatment cohort, there was a nonsignificant trend towards recurrence-free survival. A further single-center study of 207 patients who were treated with radioembolization prior to LT over a 15-year period examined long-term outcomes, including OS and recurrence-free survival (RFS) after $\mathrm{LT}^{[58]}$. Of patients initially within Milan criteria, $98 \%$ remained within Milan criteria at LT, whereas $2 \%$ progressed to UNOS T3. OS was $84 \%, 77 \%$, and $60 \%$ at 3, 5, and 10 years, respectively. Twenty-four patients had recurrent HCC with a median RFS of 120 months. Interestingly, RFS was higher in patients with 
complete or extensive tumor necrosis at pathologic evaluation in comparison to those who had partial tumor necrosis $(P<0.00001)$. Although the data are limited, additional evidence suggests the response to bridging therapy impacts post-LT outcomes, with more definitive therapies leading to complete pathologic response and predicting $\mathrm{RFS}^{[59]}$. This highlights the appeal of an ablative dosimetric approach to radioembolization in the setting of bridging to $\mathrm{LT}^{[38]}$.

\section{Downstaging for liver transplantation}

Some patients with tumor burden in excess of transplant criteria (UNOS T3) may become candidates if their tumors can be downstaged to within T2 criteria. This concept is supported by evidence showing that patients who undergo successful downstaging have similar disease-free survival as those who were originally within transplantation criteria; however, a subsequent review raised concern that downstaged patients may have a greater occurrence of post-transplantation HCC recurrence ${ }^{[60,61]}$.

Successful downstaging with radioembolization is as high as $78.9 \%^{[56]}$. When compared to chemoembolization for this indication, the results vary from similar to superior ${ }^{[61,62]}$. One systematic review found no statistical difference between the subgroup analysis of chemoembolization $v$ s. radioembolization. However, some data show that radioembolization results in superior downstaging rates compared to chemoembolization. Both are associated with a significant reduction in tumor size compared to baseline. However, in one study comparing the treatments in downstaging (T3 to T2 criteria) efficacy, significantly more patients treated with Y90 were able to reach T2 criteria $(58 \% v s .31 \%, P=0.023)^{[62]}$.

\section{Radiation lobectomy}

Patients with HCC confined to one lobe that are considered for resection may undergo radiation lobectomy with the goal of compensatory hypertrophy of the contralateral hepatic lobe, a concept first described in $2008^{[63]}$. Particularly for HCC, radiation lobectomy may offer a pathway to curative-intent therapy such as resection by causing atrophy of the treated lobe, hypertrophy of the contralateral lobe, and at the same time, treatment of the tumor and allowing a "test of time" to assess for tumor biology before subjecting the patient to resection. The size of the future liver remnant (FLR) should be between $20 \%$ and $40 \%$ of total liver volume to minimize the risk of hepatic failure after resection ${ }^{[64,65]}$. The volumetric effect, which can range from $21.2 \%$ to $57 \%$ relative hypertrophy, can be seen as early as 1 -month post-treatment, with maximal response seen at 9 months $s^{[63,65,66]}$. In comparison to the alternative therapy, portal vein embolization can provide an average of $37.9 \%$ FLR volume increase at a mean time interval of $25.9 \pm 10.1$ days ${ }^{[67]}$. However, radioembolization does have the advantage over PVE in this situation of treating the HCC and allowing time to assess for tumor biology.

\section{CONTRAINDICATIONS AND COMPLICATIONS}

Contraindications to Y90 radioembolization include severely compromised liver function (such as ChildPugh C cirrhosis) and poor performance status (Eastern Cooperative Oncology Group > 2). Impaired liver function causing hyperbilirubinemia may be a relative or absolute contraindication depending on the disease burden, hepatic distribution requiring treatment and treatment goals. Additional contraindications include hepatopulmonary shunting that results in a single treatment pulmonary dose $\geq 30$ Gy or lifetime lung dose of $\geq 50 \mathrm{~Gy}$, uncorrectable gastrointestinal perfusion at $Y 90$ administration, uncorrectable bleeding diathesis, and severe peripheral vascular disease that would prohibit arterial catheterization ${ }^{[18,68]}$.

The most common complication following radioembolization is post-embolization syndrome (fatigue, constitutional symptoms, and abdominal pain), with an incidence between $20 \%$ and $70 \%$, yet typically less severe than chemoembolization ${ }^{[32,69]}$. Though not uncommon, these adverse events are generally mild and 
self-limited. More worrisome yet less common complications include liver failure or radioembolizationinduced liver disease (REILD). Liver failure is thought to be contributed to by hepatic sinusoidal obstruction and is more commonly seen in patients who previously received chemotherapy ${ }^{[70]}$. REILD is defined as jaundice and ascites developing 1 to 2 months following radiation treatment in the absence of tumor progression or bile duct occlusion ${ }^{[31]}$. Cirrhotic liver morphology, elevated bilirubin at time of treatment, and prior use of chemotherapy are considered risk factors for the development of REILD. Overall, the incidence of REILD reporting is variable in the literature, with a rate between $1 \%-5.4 \%{ }^{[71]}$, and it is possible that incidence is decreasing with tailored patient selection and non-empiric dosimetry methods.

Inadvertent deposition of Y90 microspheres into the gastrointestinal tract may result due to the close association of the hepatic and gastrointestinal arterial beds. This complication can cause gastrointestinal injury and ulceration. Fortunately, the rate of nontarget gastrointestinal radioembolization has decreased as radioembolization techniques have improved. Although estimated at $1.9 \%-3.2 \%$, the rate of this complication may be even lower in contemporary practice ${ }^{[2,73]}$.

Other potential rare complications which typically develop after a longer time period include hepatic fibrosis and portal hypertension ${ }^{[63,74]}$, although attribution of these complications to radioembolization can be difficult, particularly in patients with underlying diffuse liver disease who may receive additional therapies over time. However, recognition of the possibility of these complications is important considerations as patients are evaluated for radioembolization.

\section{RADIOEMBOLIZATION AND SYSTEMIC THERAPY}

While Y90 radioembolization has well-established utility in the management of HCC, the landscape continues to shape. Nearly a decade, it is passed between the first available systemic therapy of sorafenib and other options. However, in the last several years, a frenzy of activity has seen the development of a number of first- and second-line options. While the SORAMIC trial comparing sorafenib to sorafenib plus radioembolization in patients with advanced HCC failed to meet its primary endpoint of overall survival benefit ${ }^{[75]}$, there is great interest in combing radioembolization with newer therapies. Recent exciting advances in systemic therapy include the development of immune checkpoint inhibitors such as nivolumab, pembrolizumab, and ipilimumab. Planned and ongoing research will help determine both the optimal combination and sequencing of therapies.

\section{CONCLUSIONS}

Y90 radioembolization is a versatile, well-tolerated therapy and plays an important role in the treatment of HCC across all tumor stages. Recognition of the dose-response relation between HCC and Y90 as well as the importance of thoughtful dosimetry has allowed for substantial advancements in radioembolization, yielding a curative-intent application and showing great promise in response rates and survival compared to simpler dosimetric approaches. The versatility of Y 90 dosimetry, therefore, allows for tailoring of therapy to the patient's needs depending on disease stage and patient goals. While Y90 radioembolization has established benefits in the management of HCC, recent exciting advances in systemic therapy options show great promise, and further research is needed to fully integrate all available therapies to optimize care for patients with HCC.

\section{DECLARATIONS}

\section{Authors' contributions}

Drafted outline: Johnson GE, Woerner AJ 
Drafted manuscript: Woerner AJ, Johnson GE

Revised manuscript: Johnson GE, Woerner AJ

Availability of data and materials

Not applicable.

\section{Financial support and sponsorship}

None.

\section{Conflicts of interest}

Johnson GE received consulting fees from Boston Scientific, Genentech and AstraZeneca. Woerner AJ declared that there are no conflicts of interest.

\section{Ethical approval and consent to participate \\ Not applicable.}

\section{Consent for publication}

Not applicable.

\section{Copyright}

(c) The Author(s) 2022.

\section{REFERENCES}

1. Jemal A, Ward EM, Johnson CJ, et al. Annual report to the nation on the status of cancer, 1975-2014, featuring survival. J Natl Cancer Inst 2017:109. DOI PubMed PMC

2. Siegel R, Ma J, Zou Z, Jemal A. Cancer statistics, 2014. CA Cancer J Clin 2014;64:9-29. DOI PubMed

3. Kulik L. Criteria for liver transplantation in hepatocellular carcinoma. Clin Liver Dis (Hoboken) 2015;6:100-2. DOI PubMed PMC

4. Villanueva A. Hepatocellular carcinoma. N Engl J Med 2019;380:1450-62. DOI PubMed

5. Llovet JM, Brú C, Bruix J. Prognosis of hepatocellular carcinoma: the BCLC staging classification. Semin Liver Dis 1999;19:329-38. DOI PubMed

6. Llovet JM, Di Bisceglie AM, Bruix J, et al; Panel of Experts in HCC-Design Clinical Trials. Design and endpoints of clinical trials in hepatocellular carcinoma. J Natl Cancer Inst 2008;100:698-711. DOI PubMed

7. Benson AB, D'Angelica MI, Abbott DE, et al. Hepatobiliary cancers, version 2.2021, NCCN Clinical practice guidelines in oncology. J Natl Compr Canc Netw 2021;19:541-65. DOI PubMed

8. Salem R, Gordon AC, Mouli S, et al. Y90 radioembolization significantly prolongs time to progression compared with chemoembolization in patients with hepatocellular carcinoma. Gastroenterology 2016;151:1155-63.e2. DOI PubMed PMC

9. Lewandowski RJ, Gabr A, Abouchaleh N, et al. Radiation segmentectomy: potential curative therapy for early hepatocellular carcinoma. Radiology 2018;287:1050-8. DOI PubMed

10. Padia SA, Johnson GE, Horton KJ, et al. Segmental yttrium-90 radioembolization versus segmental chemoembolization for localized hepatocellular carcinoma: results of a single-center, retrospective, propensity score-matched study. J Vasc Interv Radiol 2017;28:77785.e1. DOI PubMed

11. Riaz A, Gates VL, Atassi B, et al. Radiation segmentectomy: a novel approach to increase safety and efficacy of radioembolization. Int J Radiat Oncol Biol Phys 2011;79:163-71. DOI PubMed

12. Marrero JA, Kulik LM, Sirlin CB, et al. Diagnosis, staging, and management of hepatocellular carcinoma: 2018 practice guidance by the american association for the study of liver diseases. Hepatology 2018;68:723-50. DOI PubMed

13. European Association for the Study of the Liver. Electronic address: easloffice@easloffice.eu., European Association for the Study of the Liver. EASL clinical practice guidelines: management of hepatocellular carcinoma. J Hepatol 2018;69:182-236. DOI

14. Llovet JM, Real MI, Montaña X, et al. Arterial embolisation or chemoembolisation versus symptomatic treatment in patients with unresectable hepatocellular carcinoma: a randomised controlled trial. Lancet 2002;359:1734-9. DOI PubMed

15. Lo CM, Ngan H, Tso WK, et al. Randomized controlled trial of transarterial lipiodol chemoembolization for unresectable hepatocellular carcinoma. Hepatology 2002;35:1164-71. DOI PubMed

16. Sangro B, Carpanese L, Cianni R, et al; European Network on Radioembolization with Yttrium-90 Resin Microspheres (ENRY). Survival after yttrium-90 resin microsphere radioembolization of hepatocellular carcinoma across Barcelona clinic liver cancer stages: a European evaluation. Hepatology 2011;54:868-78. DOI PubMed

17. Kallini JR, Gabr A, Salem R, Lewandowski RJ. Transarterial radioembolization with yttrium-90 for the treatment of hepatocellular carcinoma. Adv Ther 2016;33:699-714. DOI PubMed PMC 
18. Tong AK, Kao YH, Too CW, Chin KF, Ng DC, Chow PK. Yttrium-90 hepatic radioembolization: clinical review and current techniques in interventional radiology and personalized dosimetry. Br J Radiol 2016;89:20150943. DOI PubMed PMC

19. Walker LA. Radioactive yttrium 90: a review of its properties, biological behavior, and clinical uses. Acta Radiol Ther Phys Biol 1964;2:302-14. DOI PubMed

20. Kennedy A, Nag S, Salem R, et al. Recommendations for radioembolization of hepatic malignancies using yttrium-90 microsphere brachytherapy: a consensus panel report from the radioembolization brachytherapy oncology consortium. Int J Radiat Oncol Biol Phys 2007;68:13-23. DOI PubMed

21. Salem R, Padia SA, Lam M, et al. Clinical and dosimetric considerations for Y90: recommendations from an international multidisciplinary working group. Eur J Nucl Med Mol Imaging 2019;46:1695-704. DOI PubMed

22. Park W, Lim DH, Paik SW, et al. Local radiotherapy for patients with unresectable hepatocellular carcinoma. Int J Radiat Oncol Biol Phys 2005;61:1143-50. DOI PubMed

23. Kim TH, Kim DY, Park JW, et al. Dose-volumetric parameters predicting radiation-induced hepatic toxicity in unresectable hepatocellular carcinoma patients treated with three-dimensional conformal radiotherapy. Int J Radiat Oncol Biol Phys 2007;67:22531. DOI PubMed

24. Son SH, Jang HS, Jo IY, et al. Significance of an increase in the Child-Pugh score after radiotherapy in patients with unresectable hepatocellular carcinoma. Radiat Oncol 2014;9:101. DOI PubMed PMC

25. Vouche M, Habib A, Ward TJ, et al. Unresectable solitary hepatocellular carcinoma not amenable to radiofrequency ablation: multicenter radiology-pathology correlation and survival of radiation segmentectomy. Hepatology 2014;60:192-201. DOI PubMed

26. Garin E, Tselikas L, Guiu B, et al. Personalised versus standard dosimetry approach of selective internal radiation therapy in patients with locally advanced hepatocellular carcinoma (DOSISPHERE-01): a randomised, multicentre, open-label phase 2 trial. Lancet Gastroenterol Hepatol 2021;6:17-29. DOI PubMed

27. Kappadath SC, Mikell J, Balagopal A, Baladandayuthapani V, Kaseb A, Mahvash A. Hepatocellular carcinoma tumor dose response after ${ }^{90}$ Y-radioembolization with glass microspheres using ${ }^{90}$ Y-SPECT/CT-based voxel dosimetry. Int J Radiat Oncol Biol Phys 2018;102:451-61. DOI PubMed

28. Song YS, Paeng JC, Kim HC, et al. PET/CT-based dosimetry in 90Y-microsphere selective internal radiation therapy: single cohort comparison with pretreatment planning on (99m)Tc-MAA imaging and correlation with treatment efficacy. Medicine (Baltimore) 2015;94:e945. DOI PubMed PMC

29. Chan KT, Alessio AM, Johnson GE, et al. Prospective trial using internal pair-production positron emission tomography to establish the yttrium-90 radioembolization dose required for response of hepatocellular carcinoma. Int J Radiat Oncol Biol Phys 2018;101:35865. DOI PubMed

30. Gabr A, Riaz A, Johnson GE, et al. Correlation of Y90-absorbed radiation dose to pathological necrosis in hepatocellular carcinoma: confirmatory multicenter analysis in 45 explants. Eur J Nucl Med Mol Imaging 2021;48:580-3. DOI PubMed

31. Gil-Alzugaray B, Chopitea A, Iñarrairaegui M, et al. Prognostic factors and prevention of radioembolization-induced liver disease. Hepatology 2013;57:1078-87. DOI PubMed

32. Riaz A, Lewandowski RJ, Kulik LM, et al. Complications following radioembolization with yttrium-90 microspheres: a comprehensive literature review. J Vasc Interv Radiol 2009;20:1121-30; quiz 1131. DOI PubMed

33. Sangro B, Martínez-Urbistondo D, Bester L, et al. Prevention and treatment of complications of selective internal radiation therapy: expert guidance and systematic review. Hepatology 2017;66:969-82. DOI PubMed

34. De la Garza-Ramos C, Overfield CJ, Montazeri SA, et al. Biochemical safety of ablative yttrium-90 radioembolization for hepatocellular carcinoma as a function of percent liver treated. J Hepatocell Carcinoma 2021;8:861-70. DOI PubMed PMC

35. Biederman DM, Titano JJ, Bishay VL, et al. Radiation segmentectomy versus TACE combined with microwave ablation for unresectable solitary hepatocellular carcinoma up to $3 \mathrm{~cm}$ : a propensity score matching study. Radiology 2017;283:895-905. DOI PubMed

36. Salem R, Johnson GE, Kim E, et al. Yttrium-90 radioembolization for the treatment of solitary, unresectable HCC: the LEGACY study. Hepatology 2021;74:2342-52. DOI PubMed PMC

37. Arndt L, Villalobos A, Wagstaff W, et al. Evaluation of medium-term efficacy of Y 90 radiation segmentectomy vs percutaneous microwave ablation in patients with solitary surgically unresectable $<4 \mathrm{~cm}$ hepatocellular carcinoma: a propensity score matched study. Cardiovasc Intervent Radiol 2021;44:401-13. DOI PubMed

38. Toskich B, Vidal LL, Olson MT, et al. Pathologic response of hepatocellular carcinoma treated with yttrium-90 glass microsphere radiation segmentectomy prior to liver transplantation: a validation study. J Vasc Interv Radiol 2021;32:518-26.e1. DOI PubMed

39. Lu DS, Raman SS, Limanond P, et al. Influence of large peritumoral vessels on outcome of radiofrequency ablation of liver tumors. $J$ Vasc Interv Radiol 2003;14:1267-74. DOI PubMed

40. Lam VW, Ng KK, Chok KS, et al. Incomplete ablation after radiofrequency ablation of hepatocellular carcinoma: analysis of risk factors and prognostic factors. Ann Surg Oncol 2008;15:782-90. DOI PubMed

41. Padia SA, Kwan SW, Roudsari B, Monsky WL, Coveler A, Harris WP. Superselective yttrium-90 radioembolization for hepatocellular carcinoma yields high response rates with minimal toxicity. J Vasc Interv Radiol 2014;25:1067-73. DOI PubMed

42. Salem R, Gilbertsen M, Butt Z, et al. Increased quality of life among hepatocellular carcinoma patients treated with radioembolization, compared with chemoembolization. Clin Gastroenterol Hepatol 2013;11:1358-65.e1. DOI PubMed

43. Salem R, Lewandowski RJ, Kulik L, et al. Radioembolization results in longer time-to-progression and reduced toxicity compared with chemoembolization in patients with hepatocellular carcinoma. Gastroenterology 2011;140:497-507.e2. DOI PubMed PMC

44. Casadei Gardini A, Tamburini E, Iñarrairaegui M, Frassineti GL, Sangro B. Radioembolization versus chemoembolization for 
unresectable hepatocellular carcinoma: a meta-analysis of randomized trials. Onco Targets Ther 2018;11:7315-21. DOI PubMed PMC

45. Salem R, Gabr A, Riaz A, et al. Institutional decision to adopt $Y 90$ as primary treatment for hepatocellular carcinoma informed by a 1,000-patient 15-year experience. Hepatology 2018;68:1429-40. DOI PubMed

46. Garin E, Rolland Y, Edeline J, et al. Personalized dosimetry with intensification using 90Y-loaded glass microsphere radioembolization induces prolonged overall survival in hepatocellular carcinoma patients with portal vein thrombosis. $J$ Nucl Med 2015;56:339-46. DOI PubMed

47. Garin E, Rolland Y, Pracht M, et al. High impact of macroaggregated albumin-based tumour dose on response and overall survival in hepatocellular carcinoma patients treated with ${ }^{90} \mathrm{Y}$-loaded glass microsphere radioembolization. Liver Int 2017;37:101-10. DOI

48. Vilgrain V, Pereira H, Assenat E, et al. Efficacy and safety of selective internal radiotherapy with yttrium-90 resin microspheres compared with sorafenib in locally advanced and inoperable hepatocellular carcinoma (SARAH): an open-label randomised controlled phase 3 trial. Lancet Oncol 2017;18:1624-36. DOI PubMed

49. Chow PKH, Gandhi M, Tan SB, et al; Asia-Pacific Hepatocellular Carcinoma Trials Group. SIRveNIB: selective internal radiation therapy versus sorafenib in Asia-Pacific patients with hepatocellular carcinoma. J Clin Oncol 2018;36:1913-21. DOI PubMed

50. Yao FY, Bass NM, Nikolai B, et al. A follow-up analysis of the pattern and predictors of dropout from the waiting list for liver transplantation in patients with hepatocellular carcinoma: implications for the current organ allocation policy. Liver Transpl 2003;9:684-92. DOI PubMed

51. Llovet JM, Bustamante J, Castells A, et al. Natural history of untreated nonsurgical hepatocellular carcinoma: rationale for the design and evaluation of therapeutic trials. Hepatology 1999;29:62-7. DOI PubMed

52. Halazun KJ, Patzer RE, Rana AA, et al. Standing the test of time: outcomes of a decade of prioritizing patients with hepatocellular carcinoma, results of the UNOS natural geographic experiment. Hepatology 2014;60:1957-62. DOI PubMed

53. Heimbach JK, Kulik LM, Finn RS, et al. AASLD guidelines for the treatment of hepatocellular carcinoma. Hepatology 2018;67:35880. DOI PubMed

54. Biederman DM, Titano JJ, Korff RA, et al. Radiation segmentectomy versus selective chemoembolization in the treatment of earlystage hepatocellular carcinoma. J Vasc Interv Radiol 2018;29:30-7.e2. DOI PubMed

55. Tohme S, Sukato D, Chen HW, et al. Yttrium-90 radioembolization as a bridge to liver transplantation: a single-institution experience. J Vasc Interv Radiol 2013;24:1632-8. DOI PubMed

56. Ettorre GM, Levi Sandri GB, Laurenzi A, et al. Yttrium-90 radioembolization for hepatocellular carcinoma prior to liver transplantation. World J Surg 2017;41:241-9. DOI PubMed

57. Gabr A, Abouchaleh N, Ali R, et al. Comparative study of post-transplant outcomes in hepatocellular carcinoma patients treated with chemoembolization or radioembolization. Eur J Radiol 2017;93:100-6. DOI PubMed

58. Gabr A, Kulik L, Mouli S, et al. Liver transplantation following yttrium-90 radioembolization: 15-year experience in 207-patient cohort. Hepatology 2021;73:998-1010. DOI PubMed

59. Agopian VG, Morshedi MM, McWilliams J, et al. Complete pathologic response to pretransplant locoregional therapy for hepatocellular carcinoma defines cancer cure after liver transplantation: analysis of 501 consecutively treated patients. Ann Surg 2015;262:536-45; discussion 543-5. DOI PubMed

60. Gordon-Weeks AN, Snaith A, Petrinic T, Friend PJ, Burls A, Silva MA. Systematic review of outcome of downstaging hepatocellular cancer before liver transplantation in patients outside the Milan criteria. Br J Surg 2011;98:1201-8. DOI PubMed

61. Parikh ND, Waljee AK, Singal AG. Downstaging hepatocellular carcinoma: a systematic review and pooled analysis. Liver Transpl 2015;21:1142-52. DOI PubMed

62. Lewandowski RJ, Kulik LM, Riaz A, et al. A comparative analysis of transarterial downstaging for hepatocellular carcinoma: chemoembolization versus radioembolization. Am J Transplant 2009;9:1920-8. DOI PubMed

63. Jakobs TF, Saleem S, Atassi B, et al. Fibrosis, portal hypertension, and hepatic volume changes induced by intra-arterial radiotherapy with 90yttrium microspheres. Dig Dis Sci 2008;53:2556-63. DOI PubMed

64. Kubota K, Makuuchi M, Kusaka K, et al. Measurement of liver volume and hepatic functional reserve as a guide to decision-making in resectional surgery for hepatic tumors. Hepatology 1997;26:1176-81. DOI PubMed

65. Vouche M, Lewandowski RJ, Atassi R, et al. Radiation lobectomy: time-dependent analysis of future liver remnant volume in unresectable liver cancer as a bridge to resection. J Hepatol 2013;59:1029-36. DOI PubMed PMC

66. Gaba RC, Lewandowski RJ, Kulik LM, et al. Radiation lobectomy: preliminary findings of hepatic volumetric response to lobar yttrium-90 radioembolization. Ann Surg Oncol 2009;16:1587-96. DOI PubMed

67. van Lienden KP, van den Esschert JW, de Graaf W, et al. Portal vein embolization before liver resection: a systematic review. Cardiovasc Intervent Radiol 2013;36:25-34. DOI PubMed PMC

68. Padia SA, Lewandowski RJ, Johnson GE, et al; Society of Interventional Radiology Standards of Practice Committee. Radioembolization of hepatic malignancies: background, quality improvement guidelines, and future directions. J Vasc Interv Radiol 2017;28:1-15. DOI PubMed

69. Riaz A, Awais R, Salem R. Side effects of yttrium-90 radioembolization. Front Oncol 2014;4:198. DOI PubMed PMC

70. Sangro B, Gil-Alzugaray B, Rodriguez J, et al. Liver disease induced by radioembolization of liver tumors: description and possible risk factors. Cancer 2008;112:1538-46. DOI PubMed

71. Kennedy AS, McNeillie P, Dezarn WA, et al. Treatment parameters and outcome in 680 treatments of internal radiation with resin 90Y-microspheres for unresectable hepatic tumors. Int J Radiat Oncol Biol Phys 2009;74:1494-500. DOI PubMed

72. Collins J, Salem R. Hepatic radioembolization complicated by gastrointestinal ulceration. Semin Intervent Radiol 2011;28:240-5. DOI 
PubMed PMC

73. Bester L, Meteling B, Pocock N, et al. Radioembolization versus standard care of hepatic metastases: comparative retrospective cohort study of survival outcomes and adverse events in salvage patients. J Vasc Interv Radiol 2012;23:96-105. DOI PubMed

74. Ayav A, Habib N, Jiao LR. Portal hypertension secondary to 90Yttrium microspheres: an unknown complication. J Clin Oncol 2005;23:8275-6. DOI PubMed

75. Ricke J, Klümpen HJ, Amthauer H, et al. Impact of combined selective internal radiation therapy and sorafenib on survival in advanced hepatocellular carcinoma. J Hepatol 2019;71:1164-74. DOI PubMed 